\title{
Observed Attenuation Rate of ELF Radio Waves
}

\author{
A. G. Jean, A. C. Murphy, J. R. Wait, and D. F. Wasmundt \\ Contribution from Central Radio Propagation Laboratory, \\ National Bureau of Standards, Boulder, Colo.
}

(Received April 27, 1961)

\begin{abstract}
Propagation attenuation rates for frequencies below $1 \mathrm{kc} / \mathrm{s}$ in the ELF region $(30 \mathrm{c} / \mathrm{s}$ to $3,000 \mathrm{c} / \mathrm{s})$ were calculated from the spectra of atmospherics observed at widely-spaced stations. Data are presented for east to west propagation under sunset approaching the eastern station. Under these conditions, the attenuation rates are about $1 \mathrm{db} / 1,000 \mathrm{~km}$ at $75 \mathrm{c} / \mathrm{s}$ and increase with increasing frequency, attaining about $3 \mathrm{db} / 1,000 \mathrm{~km}$ at $200 \mathrm{c} / \mathrm{s}$. The attenuation rates observed seem to be consistent with a two-layered ionosphere model with its lower region $90 \mathrm{~km}$ above the earth.
\end{abstract}

\section{Introduction}

It is now accepted that radio waves in the ELF (extremely low frequency) region, extending from $\mathrm{c} / \mathrm{s}$ to $3,000 \mathrm{c} / \mathrm{s}$, propagate mainly in the waveguide bounded by the earth and ionosphere in the principal or zero-order mode. In recent years, a number of workers have investigated the propagation of ELF waves using atmospherics as signals, in lieu of more suitable man-made signals [Holzer and Deal 1956, Chapman and Macario 1956, Liebermann 1957, Pierce 1960, Smith 1960, and Watt 1960].

In most of the work carried out to date, observations were made at a single station of a large number of atmospherics having their origins in lightning discharges at different ranges from the receiver. The locations of individual lightning discharges were determined using direction finding systems or, in some cases, estimates of the storm locations were arrived at from meteorological information; thus, Chapman and Macario [1956] recorded waveforms at a single station while the locations of the lightning flashes were obtained from an atmospherics direction finding network. Propagation attenuation rates were then extracted from differences between the spectra of waveforms received at different rang'es and from different sources. In this technique, some assumptions regarding the constancy of the radiation spectra of the sources must be made.

It would be of interest to determine propagation attenuation rates from waveforms of the same atmospherics observed at different ranges; especially with the observing stations lying approximately along a great circle path passing through the origin of the lightning discharges. In this favorable circumstance, fewer assumptions regarding the radiation spectra of the sources need be made.

Such observations were made recently through the cooperation of the USAF who supplied atmospheric direction finding records from which the locations and times of occurrence of individual lightning discharges were determined.

In this paper some preliminary results of atmospheric waveforms in the ELF band are presented. Data are presented here resulting from fortunate alinements of storms and two recording stations approximately along great circle paths. The resultant attenuation rates are compared with theoretical and other experimentally-determined values.

The simultaneous recordings of atmospheric waveforms of the vertical electric field were carried out at Boulder, Colorado; Fairbanks, Alaska; and Maui, Hawaii in the spring of 1960 . The equipment at each of the stations consisted of a $25 \mathrm{ft}$ vertical antenna with an isolating cathode-follower connected directly to its base. The input impedance of the cathode-follower was approximately $400 \mathrm{meg}$. A coaxial transmission line connected the output of the cathode-follower with the amplifiers located in the recording building approximately 200 feet away from the antenna. The remainder of the equipment consisted of an amplifier, filters, oscilloscope and strip-film camera. The recording equipment and its performance were the same at each station.

The overall amplitude versus frequency response of the recording apparatus, including a capacitor of $100 \mu \mu \mathrm{f}$ to simulate the antenna, is flat within $1 \mathrm{db}$ between $30 \mathrm{c} / \mathrm{s}$ and $400 \mathrm{c} / \mathrm{s}$ and within $3 \mathrm{db}$ between $15 \mathrm{c} / \mathrm{s}$ and $1 \mathrm{kc} / \mathrm{s}$ (see fig. 1). The decrease in amplitude response at the higher frequencies, to eliminate interference from transmitters operating in the VLF region, was accomplished through the use of $\mathrm{RC}$ filters. The decrease in response at frequencies below $45 \mathrm{c} / \mathrm{s}$ is a result of the time-constant of the interstage coupling capacitors and a reduction in voltage transferred from the capacitive antenna to the cathodefollower.

All of the receiving sites were located two miles or more from commercial power lines to minimize the reception of power line interference. Electrical 


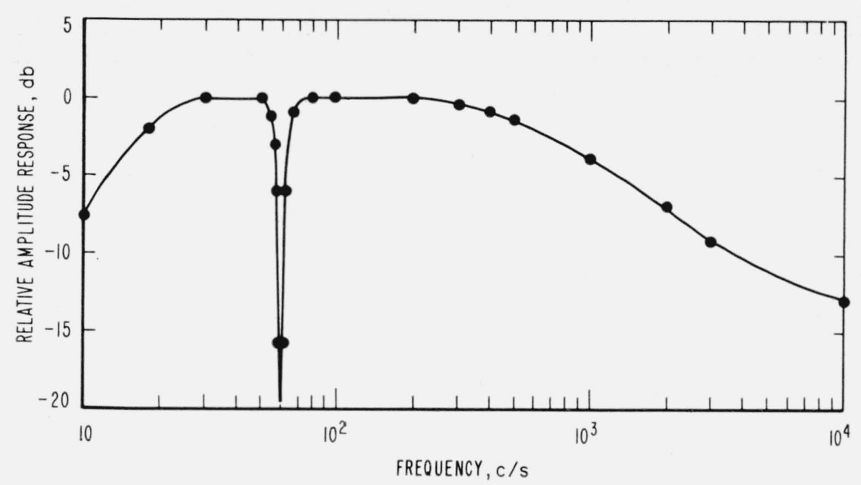

FIGURE 1. Amplitude versus frequency response of recording equipment.

power was supplied to the recording equipment by diesel-electric generators. After taking these precautions, it was found that the predominant interference was received from the distant power lines. At Maui and Boulder, the $60 \mathrm{c} / \mathrm{s}$ interference (before filtering) amounted to about $5 \mathrm{mv} / \mathrm{m}$ and $10 \mathrm{mv} / \mathrm{m}$, respectively. By comparison, the amplitude of received signals varied over a range of about 5 $\mathrm{mv} / \mathrm{m}$ to $100 \mathrm{mv} / \mathrm{m}$. It was found advantageous to use a narrow-tuned filter to reject the $60 \mathrm{c} / \mathrm{s}$ power line interference. In plotting the spectra of the atmospherics, spectral components at $60 \mathrm{c} / \mathrm{s}$ were found by interpolating from components at frequencies either side of $60 \mathrm{c} / \mathrm{s}$.

Recordings were made simultaneously at each station on continuously-moving film, which was advanced past the cathode-ray tube at a speed of $50 \mathrm{~cm} / \mathrm{sec}$. The film motion provided the sweep necessary to resolve the ELF components.

\section{Theoretical Considerations}

Let $G(t, d)$ represent the amplitude variations of an atmospheric waveform in time, $t$, and at distance, $d$, such that

$$
\mid G(t, d)=0 \text { for } t<0 \text { and } t>\tau,
$$

where $\tau$ is the duration of the waveform. The Fourier spectrum of the waveform is then

$$
E(\omega, d)=\int_{0}^{\infty} G(t, d) \cdot e^{-i \omega t} d t=\int_{0}^{\tau} G(t, d) e^{-i \omega t} d t,
$$

where $\omega$ is the angular frequency. It is assumed that the source is equivalent to a vertical dipole and that the ELF waves of interest here propagate in the earth ionosphere waveguide in the zero-order mode. The spectrum amplitude of such a pulse, propagating in the zero-order mode, can be represented by an expression of the form

$$
E(\omega, d) \cong A(\omega)[a \sin (d / a)]^{-1 / 2} e^{-\alpha(\omega) d},
$$

where $A(\omega)$ represents the amplitude spectrum of the source function, $a$ is the earth's radius in kilometers, and $\alpha(\omega)$ is the attenuation in nepers per unit distance. Equation (3) is valid at ELF provided the sources are at least $1,000 \mathrm{~km}$ from the receiving antennas [Wait, 1960]. It is also necessary, of course, that the observer is not near the antipode of the source.

If the waveform of the same atmospheric is observed at two distances, $d_{1}$ and $d_{2}$, where $d_{2}>d_{1}$, it follows that

$$
\exp \left[\alpha(\omega) \cdot\left(d_{2}-d_{1}\right)\right]=\frac{\left|E\left(\omega, d_{1}\right)\right|}{\left|E\left(\omega, d_{2}\right)\right|} \cdot\left[\frac{\sin d_{1} / a}{\sin d_{2} / a}\right]^{\frac{1}{2}} .
$$

Using this expression, the attenuation rate as a function of frequency was obtained from the spectra of atmospherics observed simultaneously at distances $d_{1}$ and $d_{2}$. Then the attenuation rate in decibels per $1,000 \mathrm{~km}$ of path length is given by

$$
\alpha(\omega)=\left[20 \log \frac{\left|E\left(\omega, d_{1}\right)\right|}{\left|E\left(\omega, d_{2}\right)\right|}-10 \log \frac{\sin d_{2} / a}{\sin d_{1} / a}\right] \cdot \frac{10^{3}}{d_{2}-d_{1}},
$$

where the logarithms are to base 10 .

The amplitude spectra of atmospheric number 1 observed at the three stations are shown in figure 2 . The spectrum of highest amplitude represents observations made at Boulder, the shortest range; the spectrum of smallest amplitude represents observations made at Maui, the greatest range; while

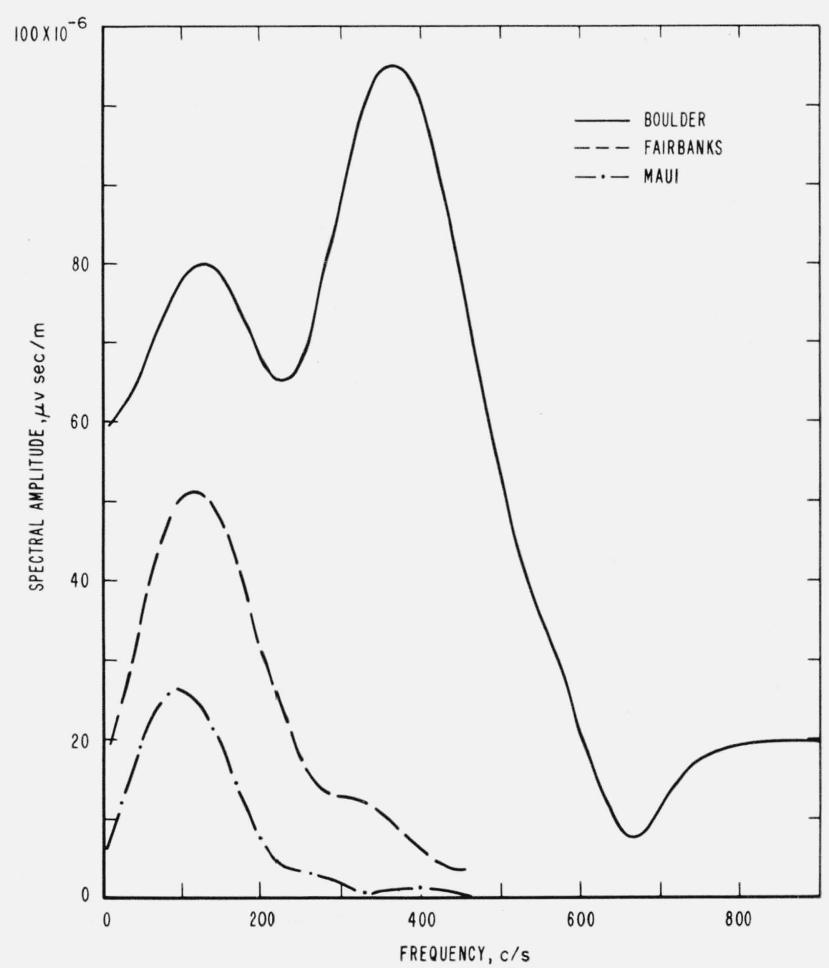

Figure 2. Amplitude spectra of atmospheric number 1 observed at Boulder, Fairbanks, and Maui. 
the intermediate values represent the Fairbanks observations. It is evident from these spectra that the frequency of peak amplitude decreases with increasing distance. For example, the frequency of maximum energy of atmospheric number 1 is about $300 \mathrm{c} / \mathrm{s}$ at $4,500 \mathrm{~km}$ and $100 \mathrm{c} / \mathrm{s}$ at $9,600 \mathrm{~km}$. It will be noted that the spectral width of the atmospheric narrows with increasing distance. The range of frequencies over which the attenuation can be calculated is limited to the width of the narrowest

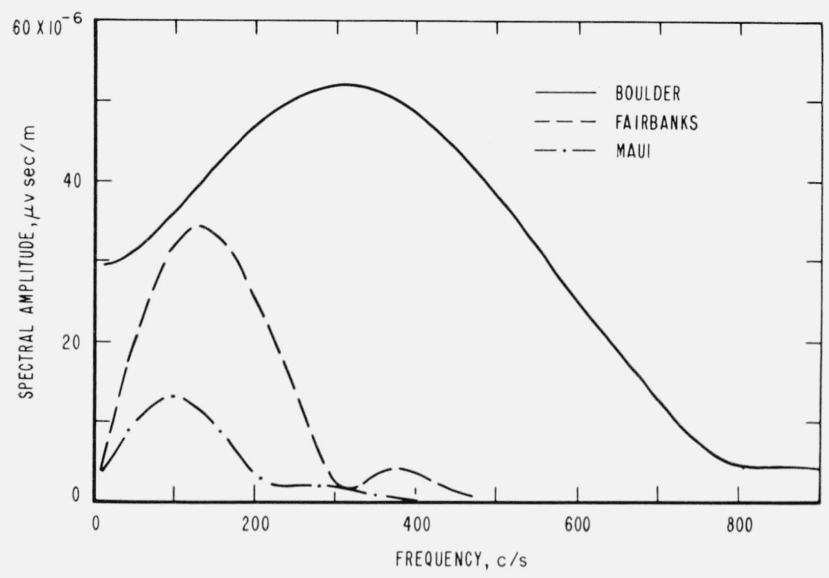

Figure 3. Amplitude spectra of atmospheric number 2.

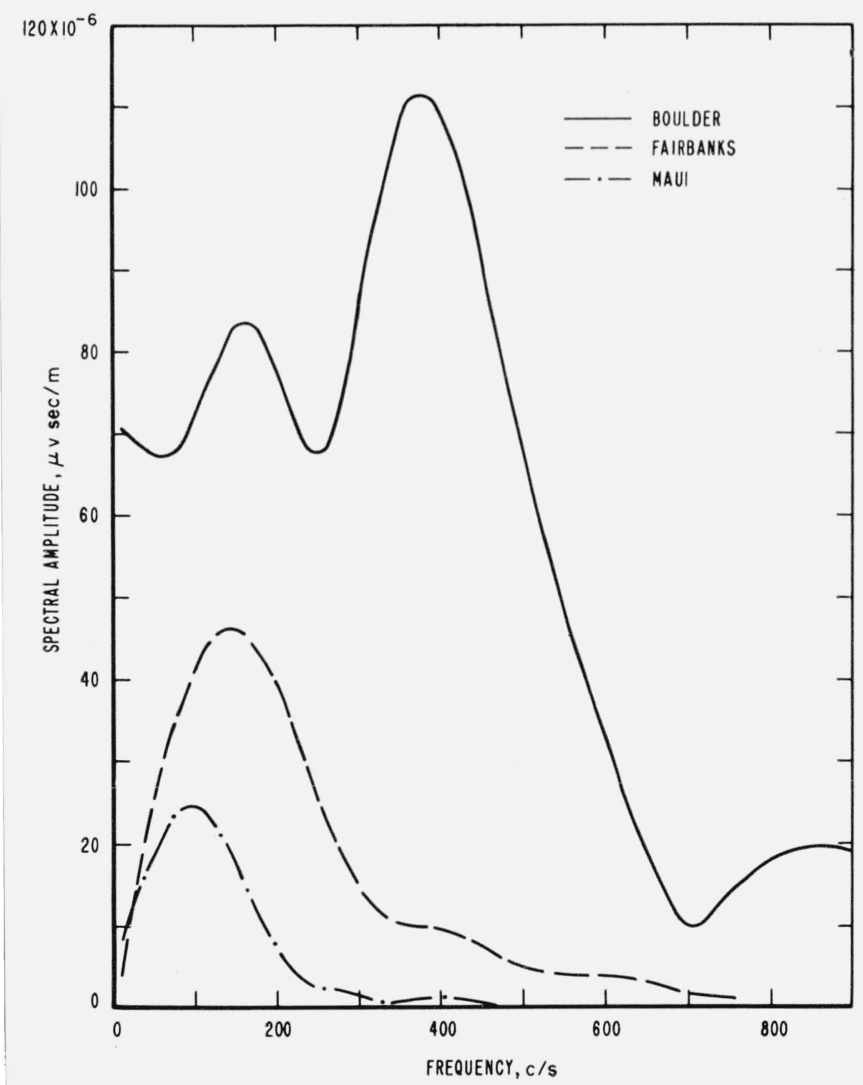

Figure 4. Amplitude spectra of atmospheric number 3. spectrum. The spectra and bandpass characteristic of the receiver indicate that the attenuation rates for the Boulder to Maui path should be valid over a frequency range of about $50 \mathrm{c} / \mathrm{s}$ to about $250 \mathrm{c} / \mathrm{s}$.

In a similar manner, the spectra of atmospherics numbers 2, 3, and 4, observed at Boulder, Fairbanks, and Maui, are given in figures 3, 4, and 5 .

In figure 6 , the propagation attenuation rates in $\mathrm{db} / 1,000 \mathrm{~km}$ derived from atmospherics numbered $1,2,3$, and 4 are plotted against frequency for the

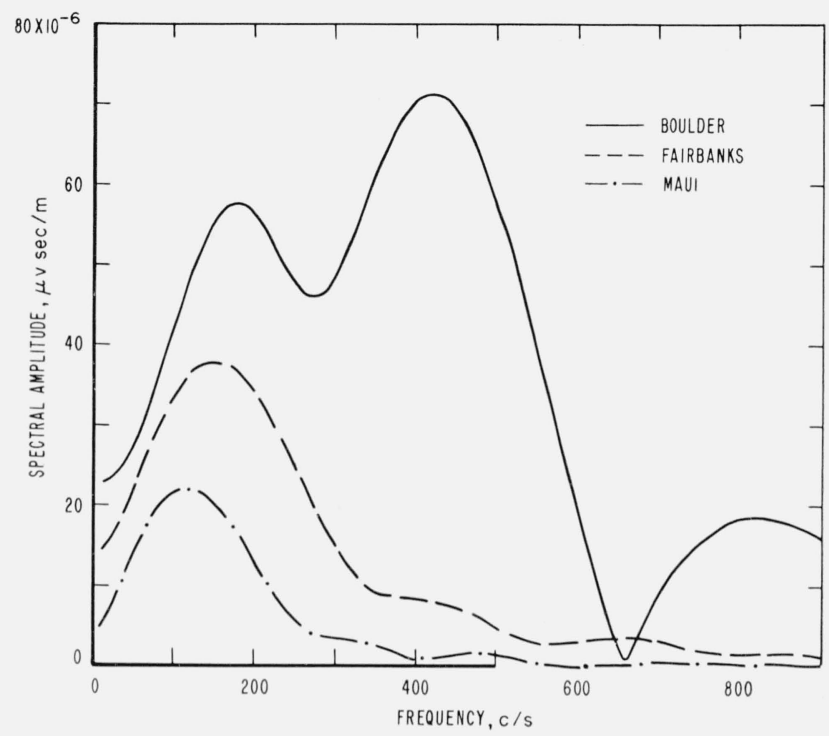

Figure 5. Amplitude spectra of atmospheric number 4.

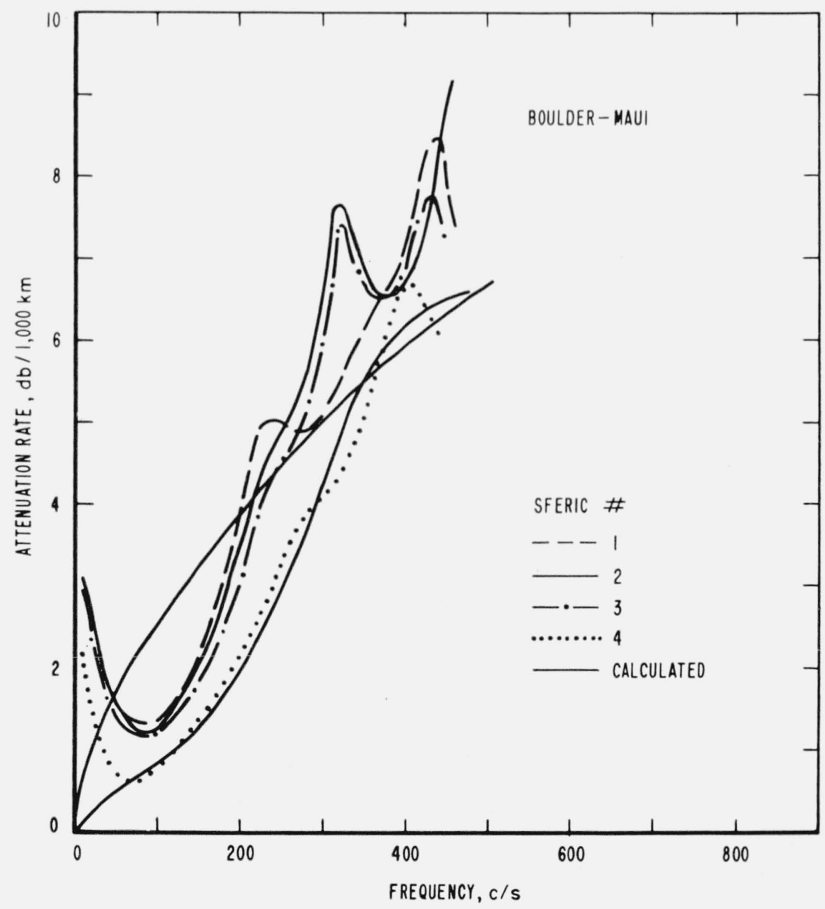

Figure 6. Propagation attenuation rates versus frequency derived from atmospherics 1-4 compared with calculated rates (see text). 
Boulder to Maui pair. Attenuation rates derived from numbers 1,2 , and 3 were recorded when sunset was at the eastern end of the path (1835 MST) and have minimum values of about $1.25 \mathrm{db} / 1,000 \mathrm{~km}$ near $75 \mathrm{c} / \mathrm{s}$. Somewhat lower rates are observed at $75 \mathrm{c} / \mathrm{s}$ for atmospheric number 4 which was recorded an hour later. It is tempting to attribute the lower attenuation rate observed at 1935 to the increased amount of darkness along the path - although the occurrence of sunset along the path complicates the situation.

\section{Presentation and Discussion of Results}

During two, 2-minute recording intervals beginning 1835 and 1935 MST on March 8, 1960, waveforms of five atmospherics were recorded at Boulder, Maui, and Fairbanks from storms in the Atlantic Ocean at approximately $39^{\circ} \mathrm{N}$ and $58^{\circ} \mathrm{W}$. This information is tabulated below.

\begin{tabular}{|c|c|c|c|c|}
\hline \multicolumn{2}{|c|}{ Atmospheric } & \multicolumn{2}{|c|}{$\begin{array}{l}\text { Approximate range } \\
\text { from source to }\end{array}$} & \multirow{2}{*}{$\begin{array}{c}\text { Time of reception } \\
\text { of atmospheric at } \\
\text { Boulder }\end{array}$} \\
\hline No. & Location & Boulder & Maui & \\
\hline $\begin{array}{l}1 \\
2 \\
3 \\
4\end{array}$ & $\begin{array}{l}39^{\circ} \mathrm{N}, 59^{\circ} \mathrm{W} \\
39^{\circ} \mathrm{N}, 65^{\circ} \mathrm{W} \\
37^{\circ} \mathrm{N}, 61^{\circ} \mathrm{W} \\
39^{\circ} \mathrm{N}, 58^{\circ} \mathrm{W}\end{array}$ & $\begin{array}{l}4500 \\
3500 \\
3500 \\
4500\end{array}$ & $\begin{array}{l}9600 \\
8700 \\
8800 \\
9600\end{array}$ & $\begin{array}{l}1835: 52 \text { MST } \\
1836: 25 \\
1836: 07 \\
1935: 58\end{array}$ \\
\hline
\end{tabular}

The propagation paths from the sources to Boulder were in darkness. At the time of the first observation (1835 MST), ground sunset was approximately 600 $\mathrm{km}$ west of Boulder and approximately $1,900 \mathrm{~km}$ west of Boulder during the second observation. In the first case, approximately 90 percent of the path from Boulder to Maui was in daylight; in the second case, approximately 75 percent of the path from Boulder to Maui was in daylight.

The paths of propagation from the lightning discharges to Boulder and Maui, respectively, are approximately east-to-west and transverse to the earth's magnetic field. Waveform observations were also made at Fairbanks, Alaska and attenuation rates were calculated from the Boulder and Fairbanks data also, although this is a less favorable situation since the paths of propagation are not along great circle paths.

As a matter of interest, calculated attenuation curves are also shown in figure 6 . A two layer ionospheric model [Wait 1958] is employed; the height of the bottom of the reflecting layer is denoted $h$, and the effective conductivity parameter is $\omega_{r}^{\prime}$. At height $d$ above this, the effective conductivity is assumed to jump to a new value of $\omega_{r}^{\prime \prime}$. The curves shown in figure 6 correspond to the two cases where

$$
\text { (i) } \omega_{r}^{\prime}=10^{5}, \quad h=90 \mathrm{~km}, d=\infty \quad \text { (upper calculated }
$$

(ii) $\omega_{r}^{\prime}=10^{5}, h=90 \mathrm{~km}, d=20 \mathrm{~km}$ (lower calculated curve)

$$
\omega_{r}^{\prime \prime}=10^{6}
$$

The first of these cases corresponds, of course, to a homogeneous ionosphere. The resulting attenuation should be proportional to (frequency) $)^{\frac{1}{2}}$. This would lead to a convex curve which is clearly not in accord with the data. The second of these curves has the required form; the ionosphere is thus behaving as a stratified conductor. For the lower frequencies, the upper well-conducting layer is becoming effective and the attenuation is reduced. Of course, other combinations of $d$ and $\omega_{r}^{\prime \prime}$ could be chosen to fit the facts, but it would always be necessary to have the effective conductivity increase with height in some manner.

An average of the attenuation rates observed for the Boulder to Maui path is shown in figure 7 (solid line). There appears to be minimum in the attenuation rate of about $1.0 \mathrm{db} / 1,000 \mathrm{~km}$ of path length near $70 \mathrm{c} / \mathrm{s}$. The rate increases with increasing frequency attaining values of about $1.5 \mathrm{db} / 1,000 \mathrm{~km}$ at $135 \mathrm{c} / \mathrm{s}, 2 \mathrm{db}$ at $160 \mathrm{c} / \mathrm{s}$, etc. The increase in observed attenuation at frequencies below $70 \mathrm{c} / \mathrm{s}$ is doubtful; it is thought that the data are influenced by noise at frequencies below about $70 \mathrm{c} / \mathrm{s}$. However, it is possible to construct a layer model which does have an attenuation increase as the frequency becomes very much lower. Such a model might consist of a three-layer ionosphere with parameters $\omega_{r}^{\prime}, \omega_{r}^{\prime \prime}$, and $\omega_{r}^{\prime \prime \prime}$. If $\omega_{r}^{\prime \prime \prime}$ is taken to be somewhat less than $\omega_{r}^{\prime \prime}$ and $\omega_{r}^{\prime}$, a lower frequency will be reached where the attenuation is controlled by the outermost layer of conductivity $\omega_{r}^{\prime \prime \prime}$ [Wait 1957]. It is also possible that heavy ions may influence the results in frequencies below $100 \mathrm{c} / \mathrm{s}$.

Attenuation rates derived from the Boulder to Fairbanks and Fairbanks to Maui data are also plotted in figure 7 . These data are subject to additional limitations in interpretations; however, the rates are about the same as those presented for the largely sea-water Boulder to Maui path. In view of the theory for ELF propagation [Wait, 1960], the effects due to ground conductivity would be expected to be small if present.

The propagation attenuation rates in figure 7 are compared with more complete data for day and for night by Chapman and Macario in figure 8 . The present data plots between the daytime and nighttime values reported by Chapman and Macario. Perhaps this is to be expected since the paths were partially dark at the east end, and in daylight to the west. It is of interest to recall that the Chapman and Macario data were recorded at ranges up to $4,000 \mathrm{~km}$ while the present data results from observations at a minimum range of about $4,000 \mathrm{~km}$ and a maximum range of about $10,000 \mathrm{~km}$. Although the present data are not very comprehensive, they do confirm attenuation rates resulting from other experiments using different techniques. In addition, the feasibility of deriving propagation data at ELF from spectral analyses of atmospherics is established. 


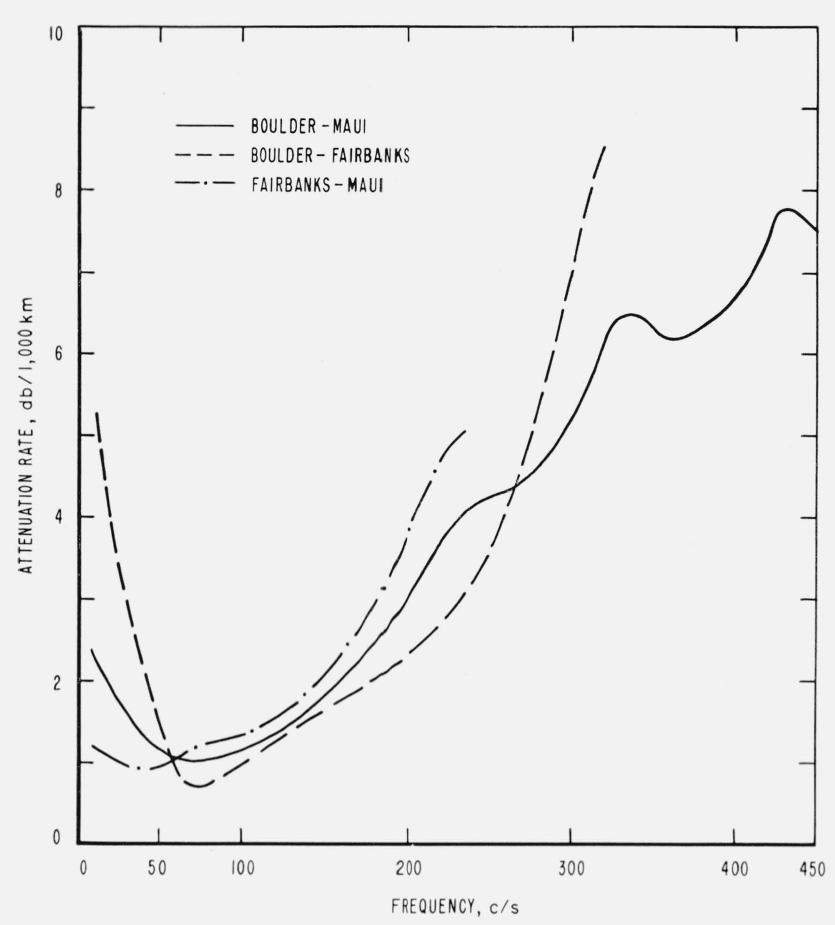

FiguRe 7. Average of propagation attenuation rates versus frequency for atmospherics 1-4.

\section{References}

Chapman, F. W. and R. C. V. Macario, Propagation of audiofrequency radio waves to great distances, Nature $\mathbf{1 7 8 , 9 3 0 ( 1 9 5 6 )}$

Holzer, R. E. and O. E. Deal, Low audiofrequency electromagnetic signals of natural origin, Nature 17\%, 536 (1956).

Liebermann, L., Anomalous propagation below $500 \mathrm{c} / \mathrm{s}$, Symp. Prop. VLF Radio Waves 3, No. 25, Boulder, Colo. (1957)

Pierce, E. T., Some ELF phenomena, J. Research NBS 64D, No. 4, 383-386 (July-Aug. 1960)

Smith, E. J., The propagation of low-audio frequency electromagnetic waves, Ph. D. dissertation, Univ. of Calif. at Los Angeles, Feb. 1960.

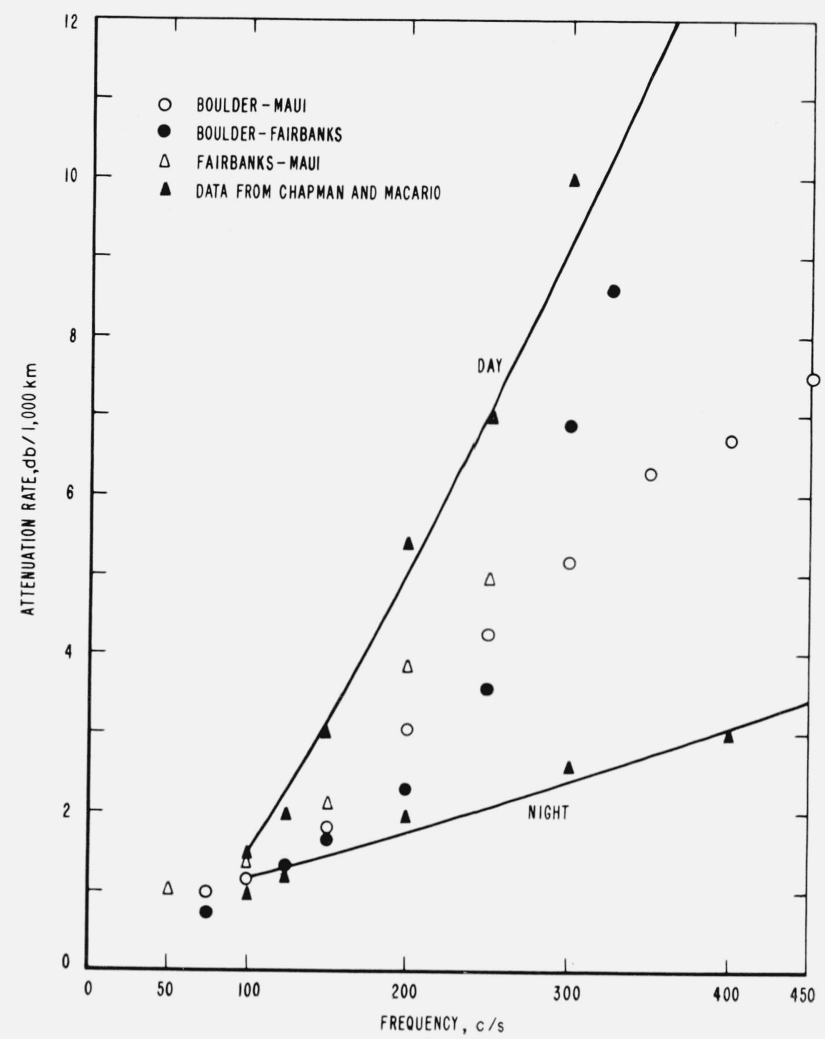

FIgure 8. Comparison of figure $\gamma$ propagation attenuation rates with Chapman and Macario Data.

Wait, J. R., The mode theory of VLF ionospheric propagation for finite ground conductivity, Proc. IRE $\mathbf{4 5}, 760$ (1957)

Wait, J. R., An extension to the mode theory of VLF ionospheric propagation, J. Geophys. Research 63, 125 (1958).

Wait, J. R., Mode theory on the propagation of ELF radio waves, J.'Research NBS 64D, 387-404 (July-Aug. 1960)

Watt, A. D., ELF electric fields from thunderstorms, J. Research NBS 64D, No. 5, 425-434 (Sept.-Oct. 1960).

(Paper 65D5-153) 